\title{
SOCIEDADE DO CONHECIMENTO, ESCALAS DE GOVERNO E GOVERNANÇA TERRITORIAL: UM ENSAIO EXPLORATÓRIO E PROSPECTIVO PARA A SOCIEDADE PORTUGUESA ${ }^{1}$
}

\author{
António M. A. Covas ${ }^{2}$ \\ Maria das Mercês C. M. Covas
}

\begin{abstract}
RESUMO
Estamos em plena crise de governança territorial e os sistemas de multi-level governance $(M L G)$ não estão a funcionar. Estas disfunções são mais visíveis nas sociedades periféricas do sistema capitalista. Em Portugal, à crise do capitalismo global (2007-2008), juntámos uma crise de ajustamento (2011-2014) típica da zona euro, uma crise de reestruturação do modelo de crescimento (2000-2015) e, finalmente, uma crise do modelo de governança territorial (2011-2015) que deverá ou deveria suportar esse novo modelo de crescimento. Esta comunicação tem um carácter exploratório e prospectivo no sentido de delimitar as balizas que nos permitem perceber melhor como, na sociedade do conhecimento e na sociedade em rede, se processam as mudanças nas escalas de governo (rescaling), na gestão do território (territorial governance) e, também, nas percepções dos cidadãos (collaborative commons and networking). Em pano de fundo, a multi-level governance (MLG) europeia e os cenários mais prováveis da geogovernança portuguesa.
\end{abstract}

Palavra-Chave: Governação multiníveis. Rescaling. Bens comuns. Coopetição.

\section{KNOWLEDGE SOCIETY, SCALES OF GOVERNENCE AND TERRITORIAL GOVERNENCE: THE PORTUGUESE SOCIETY IN TRANSITION}

\section{SUMMARY}

We are in a crisis of territorial governance and the multi-level governance systems do not work very well as we can see them in the peripheral societies of the capitalist system. In Portugal, to the crisis of global capitalism (2007-2008) we have joined an adjustment crisis (2011-2014) within the Eurozone, a restructuring crisis in the growth model (2000-2015) and finally a governance crisis as a whole. In this context, the portuguese society is clearly blocked. This paper has a preliminary and prospective purpose aiming at to better understand

\footnotetext{
${ }^{1} \mathrm{O}$ artigo que agora se publica, com algumas alterações, é uma adaptação da comunicação dos autores apresentada no II Congresso Internacional SETED-ANTE, intitulada «Sociedade do conhecimento, escalas de governo e governança territorial: a sociedade portuguesa em transição», que decorreu em Santiago de Compostela, 1-3 de Julho de 2015 (COVAS; COVAS, 2015b). Os autores escrevem de acordo com a antiga ortografia da língua portuguesa.

${ }^{2}$ Economista, professor Catedrático da Universidade do Algarve, Faculdade de Economia e Investigador do Centro de Investigação sobre o Espaço e as Organizações (CIEO) - Universidade do Algarve (UALG). Portugal. E-mail: acovas@ualg.pt.

${ }^{3}$ Socióloga, professora Associada e Investigadora do Centro de Investigação sobre o Espaço e as Organizações (CIEO) - Universidade do Algarve. Portugal. E-mail: mcovas@ualg.pt.
}

DRd - Desenvolvimento Regional em debate (ISSNe 2237-9029) 
the different scales of government, the rescaling and territorial networking and the collaborative commons, within the general framework of the European multi-level governance and the scenarios of the portuguese geogovernance.

KEY WORDS: Multi-level governance. Rescaling. collaborative commons. Coopetition.

\section{INTRODUÇÃO: GOVERNAÇÃO MULTINÍVEIS, O ESTADO DA ARTE}

$\mathrm{Na}$ literatura científica, muitos autores alertaram, em devido tempo, para as grandes mudanças que iriam ocorrer nas sociedades do século XXI, em termos organizacionais e comportamentais, na vida quotidiana, presente e futura, e para os riscos que elas comportam. Vão nesse sentido as obras de Jurgen HABERMAS (2010, 2009, 2006, 1998b, 1996b, 1992, 1991, 1988, 1989, 1986b, 1985a, 1985b, 1983, 1981b, 1981a, 1976b, 1973, 1968, 1962), Peter BERGER e Thomas LUCKMANN (1967), Herman DALY e John COBB (DALY e COBB,1989), Francis FUKUYAMA (1992), Paul VIRILIO (1996), Anthony GIDDENS (1999), Manuel CASTELLS (2000a, 2000b, 2000c), Oliver WILLIAMSON (2000), Karl POLANY (2000), Pierre BOURDIEU (2000), Zigmunt BAUMAN (2001), Ulrick BECK, Antony GIDDENS e Scott LASH (2004), François EYMARD-DUVERNEY (2006), Gilles LIPOVETSKY, $(2015,2006,2005)$, Gilles LIPOVETSKY e Jean SERROY (LIPOVETSKY, G.; SERROY, J., 2014, 2010a, 2010b), Rogerio HAESBAERT (2006), Thomas FRIEDMAN (2008, 2006), Joel de ROSNAY (2012), Jeremy RIFKIN (2014a, 2014b, 2001, 1998, 1996), Daniel INNERARITY (2011, 2010, 2009, 2005), Ulrick BECK (2009, 2006, 2002, 1999, 1992), Bernard PECQUEUR e Jean-Benoît ZIMMERMANN (2004), Elinor OSTROM (2005a, 2005b), Neil FLIGSTEIN (2012, 2001), M. KEATING (2013), António COVAS (2015a, 2015b, 2013, 2009, 2003), António COVAS e Mercês COVAS (COVAS e COVAS, 2015a, 2015b, 2014a, 2014b, 2014c, 2014d, 2014e, 2013a, 2013b, 2013c, 2012, 2011), Margarida PEREIRA (2013, 2009), Valdir DALLABRIDA (2013, 2012, 2011), entre muitos outros autores.

Nas obras mais recentes, aqui mencionadas, a governação multiníveis adquire cada vez mais visibilidade do ponto de vista teórico, metodológico e de práticas de investigaçãoacção, potencialmente mais inovadoras, permitindo assim, alargar o campo de possibilidades de estudo, intervenção e participação territoriais. O esforço continuado e a aquisição constante de conhecimento sobre a governação multiníveis colocam esta temática num patamar muito exigente e inovador, nomeadamente, nas áreas ligadas à criação de territórios inteligentes, de territórios-rede, do desenvolvimento territorial, regional e local, abrindo-a a novos objectos e campos de estudo, experimentação e investigação-acção, aplicáveis à análise de governação multiníveis de territórios actuais ou a estudos prospectivos sobre novos sistemas político administrativos territoriais.

Os sistemas político-administrativos do território deixaram de ser uma variável exógena do processo mais geral de modernização das instituições políticas. No século XXI, a "tecnologia política" do Estado-administração está sujeita a uma pressão e obsolescência constantes se pensarmos, por exemplo, na sociedade da informação e do conhecimento, nos movimentos de globalização, de integração regional supranacional e de descentralização 
infranacional, no conjunto, aquilo que hoje a literatura designa como processos e procedimentos de governação multiníveis ou multi-level governance.

A sociedade portuguesa está num impasse no que diz respeito ao modelo de administração do seu território. Estamos em plena crise de governança territorial e os sistemas de multi-level governance não estão a funcionar. Estas disfunções são mais visíveis nas sociedades periféricas do sistema capitalista.

Em Portugal, à crise do capitalismo global (2007-2008), juntámos uma crise de ajustamento (2011-2014) típica da zona euro, uma crise de reestruturação do modelo de crescimento (2000-2015) e, finalmente, uma crise do modelo de governança territorial (20112015), parte importante de uma reforma do Estado que tarda e que deverá ou deveria suportar esse novo modelo de crescimento. Manifestamente, muitas variáveis para poucas equações e a sociedade portuguesa está num verdadeiro impasse.

Os factores que, entretanto, precipitaram esta turbulência são bem conhecidos: a competição agressiva dos actores globais (global players), a condicionalidade crescente das instituições europeias por causa dos nossos eternos desequilíbrios, a inadaptação aos universos virtuais e às redes digitais da sociedade da informação e do conhecimento, a pressão constante das entidades infranacionais por mais recursos, o criticismo permanente dos movimentos sociais e culturais e a sua indiferença e indignação face à política partidária. Tudo isto, para lá dos erros próprios, que foram muitos e graves. Por todas estas razões, não surpreende que tenha subido o custo de oportunidade da despesa pública e que a dimensão do Estado, medida pelo nível da sua despesa pública, da sua carga fiscal e do seu stock de dívida, seja hoje claramente excessiva face à dimensão da sua economia e da sua sociedade civil.

Estamos, portanto, numa verdadeira encruzilhada. No plano interno, a democracia doméstica é impotente para modificar o curso dos acontecimentos, no plano europeu vivemos uma espécie de liberdade condicional que nos tolhe os movimentos, no plano global, finalmente, faltam as instituições multilaterais acreditadas para levar a efeito uma verdadeira política regulatória.

Por estas razões, todas as instâncias de governo e administração parecem estar de acordo quanto à imprescindibilidade de uma governação multiníveis eficaz (multi-level governance) que seja capaz de criar benefícios de contexto para todos os territórios e que, ao mesmo tempo, regule os novos custos de formalidade e transacção de tal modo que as exigências processuais e procedimentais supervenientes não se transformem em novas fontes de discriminação e segregação territoriais.

À medida que os mercados globais se expandem e os riscos globais se intensificam alarga-se o perímetro de incerteza e insegurança que rodeia os diversos sistemas democráticos domésticos e os respectivos territórios locais e regionais. Doravante, não há sistemas produtivos locais e regionais, por mais longínquos que se encontrem, imunes a estas vagas de incerteza e insegurança. Este facto, grave e sério, exige que se experimentem e desenvolvam diferentes abordagens de multi-level governance a vários níveis de governo e administração, em particular, com novas experiências de multiterritorialidade e cooperação territorial descentralizada no âmbito dos chamados territórios-rede (COVAS; COVAS, 2014a, 2014d) e no quadro de novas modalidades de economia convencional e contratual entre os vários parceiros em presença. 
À medida que se aprofunda a sociedade da informação e do conhecimento (SIC) aprofunda-se, também, a lógica plural de múltiplas formas de acção colectiva. As sociedades em rede colaborativa podem ajudar a mitigar a incerteza e insegurança veiculadas pelos mercados e os riscos globais e no seu seio podem funcionar instituições intermédias de mediação e regulação (buffer institutions) ${ }^{4}$ que sejam capazes de prevenir e amortecer o impacto das externalidades negativas e do risco moral mas, igualmente, de promover os benefícios de contexto e as novas multiterritorialidades emergentes. Neste contexto, a governação multiníveis (multi-level governance), a cooperação territorial descentralizada $(\mathrm{CTD})^{5}$, a multiterritorialidade dos territórios-rede, a economia das convenções e dos contratos e as redes sociais colaborativas são formas específicas de buffer institutions. Estas opções e formatos institucionais ajudam a adaptar, a mitigar e a reconverter a economia dos territórios locais e regionais que se encontram, cada vez mais, à beira de um ataque de nervos (COVAS, 2009).

\section{A SOCIEDADE DA INFORMAÇÃO E DO CONHECIMENTO E AS MUTAÇÕES DO TERRITÓRIO}

No próximo futuro, iremos, muito provavelmente, revisitar o conceito de poder autárquico no sentido de um poder mais lateral e colaborativo, de um par interpares, agindo, simultaneamente, em comunidades reais, em plataformas digitais, redes sociais e comunidades online. Esta abertura aumentará o espaço de liberdade e o campo das possibilidades e soluções do município do século XXI, em direcção à composição de territórios-rede de geometria mais variável. Teremos, assim, um município sem fronteiras e mais cosmopolita, mais interactivo com os seus concidadãos, com mais economia verde e economia azul, mais criativo e cultural, menos fiscalista e mais contratualista no plano financeiro. Em consequência, a sua organização interna e a sua gestão sofrerão uma pequena revolução, não apenas na estrutura orgânico-funcional e na relação entre o back office e o front office mas, sobretudo, na sua cultura digital e colaborativa, isto é, na estratégia de informação, comunicação e interacção face às redes colaborativas de que fará parte e que, doravante, constituirão o novo ecossistema institucional de acolhimento (COVAS, 2015b) e (COVAS; COVAS, 2015a).

A nossa revisitação do poder autárquico não se limita, porém, à nova cultura da gestão municipal, mais aberta, reticulada e colaborativa, ela estende-se, também, à reforma do poder territorial no seu conjunto, aos diferentes níveis, no quadro da reforma do Estadoadministração em curso, sem a qual a gestão municipal perde clareza, fulgor e profundidade.

\footnotetext{
${ }^{4}$ Instituições intermédias de mediação e regulação (buffer institutions) são instituições formais ou informais que servem de amortecedores locais dos efeitos nocivos inesperados provocados por decisões tomadas a nível global.

${ }^{5}$ Para aprofundar os conceitos de cooperação territorial descentralizada (CTD) e de coopetição interregional (CI) e as suas funcionalidades e aplicações, ver António Covas (COVAS, 2009: 388-396). O autor considera a cooperação territorial descentralizada (CTD) como um instrumento essencial para organizar a coopetição interregional, a um tempo, a cooperação territorial para fazer face ao paradigma dos riscos globais e a competição cooperativa para fazer face ao paradigma dos mercados globais.
}

DRd - Desenvolvimento Regional em debate (ISSNe 2237-9029)

v. 5, n. 2, p. 25-47, jul./dez. 2015. 
Para o poder local o futuro acontecerá em três grandes planos. Em primeiro lugar, no plano tecnológico e técnico-administrativo, com mudanças incrementais que dependem também de recursos financeiros disponíveis. Três grandes vectores afectarão a estrutura técnica e tecnológica do poder local tal como o conhecemos hoje: a automação, a desmaterialização e a desintermediação. Estas alterações funcionais modificarão substancialmente a estrutura técnico-administrativa e o capital social das autarquias locais.

Em segundo plano, o que poderíamos designar como o ecossistema comunitário que rodeia o poder local e que se reporta ao universo associativo e às redes colaborativas que ligam esse universo associativo, seja do lado da oferta, mais comum, ou do lado da procura, menos comum mas mais necessário no novo contexto. Falamos da politics do poder local. Trata-se aqui de criar o complexo digital e colaborativo da administração local interagindo mais com os cidadãos e as suas organizações, muito provavelmente em plataformas de outsourcing muito diversas e imaginativas, forjando, assim, a nova policy do poder local. Aliás, acreditamos que a expressão autarquia local passará de moda por invocar autarcia, hierarquia e autoridade. Para já, a única certeza que temos hoje é a de que haverá mais pluralidade e diversidade de poderes locais e que essa nova realidade mudará gradualmente a face do poder autárquico tal como o conhecemos hoje. Em 2025, o poder local estará irreconhecível. Para melhor.

O terceiro plano, que poderíamos designar de ecossistema institucional, a polity do poder local, é uma ampla zona cinzenta onde se realizam as principais transacções entre níveis de governo e administração, o que a literatura consagrou com as designações de governação multiníveis e multi-escalaridade. Aqui falamos de federalismo autárquico, de comunidades intermunicipais, das diversas modalidades de regionalização, nacionais e transfronteiriças, das alterações da condicionalidade europeia em matéria de coesão territorial e até de reforma do Estado (COVAS, 2015b) e (COVAS; COVAS, 2015a).

Em síntese, as mutações territoriais do poder local e regional e a sua gestão multiterritorial dependerão muito da organização e interacção da sociedade política local com o poder autárquico; em primeiro lugar, a relevância do universo associativo e das redes colaborativas, em segundo lugar, da política interna do município e de suas políticas locais e intermunicipais e, em terceiro, da articulação multiníveis de governo e administração nos planos sub-regional, regional e nacional, seja no que diz respeito à produção de ambientes acolhedores ou de externalidades positivas.

\section{A POLÍTICA DE COESÃO TERRITORIAL NA RESSACA DA CRISE SISTÉMICA DE 2007-2008}

A política de coesão territorial é um compromisso entre a lógica dos mercados, globalizante, e a lógica dos territórios, particularista. Num sistema de governo e administração a três níveis - supranacional, nacional, regional - as instituições do centro têm, geralmente, uma tendência racionalizadora enquanto as colectividades territoriais tendem, naturalmente, para a diferenciação e, no limite, para a discriminação. Na ressaca da crise sistémica de 20072008, que ainda permanece, paira uma grande incógnita sobre o futuro da política de coesão da União Europeia, por isso, importa reter alguns factores contextuais que não deixarão de 
marcar a evolução do sistema de política regional e a cooperação territorial dos Estadosmembros no próximo futuro.

-Primeira questão: esta crise sistémica de enorme amplitude teve, desde logo, uma consequência, a saber, a uma maior governamentalização do processo de tomada de decisão; assim a designada Europa das Regiões foi relegada para plano secundário e irá ficar em compasso de espera muito mais tempo.

-Segunda questão: apesar do tratado de Lisboa, a crise sistémica provocou uma erosão da componente parlamentar do sistema político, em particular ao nível dos Parlamentos nacionais e dos Parlamentos regionais; isto é, apesar do tratado de Lisboa, o défice de controlo parlamentar, durante a crise e na ressaca da crise, pode transformar-se numa fonte potencial de mal-estar para o sistema europeu de cooperação territorial.

- Terceira questão: na ressaca da crise sistémica, não sabemos que pacto de estabilidade e crescimento (PEC) poderá melhor corresponder às necessidades de recuperação económica das regiões, sendo que, por esta via, se pode pôr em causa o contributo indispensável da cooperação territorial para o desenvolvimento das regiões, assim como os processos de descentralização político-administrativa nos Estados de estrutura política mais centralizada.

-Quarta questão: na ressaca da crise sistémica, a forma diferenciada como os Estados membros estão politicamente constituídos (federais, regionais e unitários) permite receber e aplicar o princípio de subsidiariedade de modo diferente; aparentemente, os Estados federais e regionais estão politicamente e orçamentalmente melhor apetrechados para receber e aplicar, com mais qualidade e eficiência, uma política regional pós-crise seja qual for o seu figurino no quadro da União Europeia.

-Quinta questão: face às consequências mais gravosas da crise sistémica, uma política de coesão regional territorialmente mais descentralizada e cooperativa pode surgir como um espaço de concertação de iniciativas e projectos, associada a fórmulas organizativas mais inovadoras libertas da tutela administrativa mais conservadora e tradicional.

-Sexta questão: numa fase ainda pré-federal, a política de coesão regional pode coabitar, com dificuldade, com os programas de estabilidade e convergência, sobretudo nos países com acentuadas assimetrias regionais; na ressaca da crise sistémica, podemos assistir a uma fase caótica de regional governance em choque com a política de concorrência e, quase inevitavelmente, a uma sobreposição de políticas regionais, correspondendo não apenas a diferentes enfoques políticos do problema regional como, também, a vários modos de «traficar» recursos escassos.

-Sétima questão: na ressaca da crise sistémica, e na ausência de um ciclo longo de prosperidade socioeconómica que atenue as assimetrias regionais e os focos negativos de regionalismo, a distância que separa o regionalismo do nacionalismo político pode encurtar-se dramaticamente. 
-Oitava questão: a insegurança do Estado nacional motivada pela dupla transferência de poderes, para o centro comunitário e para a periferia infranacional, pode ver-se subitamente agravada pela emergência de regionalismos de raiz históricocultural, étnica e religiosa; na ressaca da crise sistémica, a política regional pode ser obrigada a assumir uma estratégia de emergência em defesa do Estado nacional; neste quadro, a lógica comunitária deve contribuir para a governabilidade de um multi-level system pilotado e regulado pelos Estados nacionais e a própria União.

-Nona questão: na ressaca da crise sistémica, o reforço da ajuda à fronteira exterior da União, primeira porta de entrada de eventuais fluxos erráticos de população daquelas zonas, é fundamental para prevenir os populismos e regionalismos emergentes que, por esta via, podem receber argumentos adicionais para adquirirem uma legitimidade renovada.

-Décima questão: no âmbito da política de relações exteriores e segurança comum, esta outra faceta da política regional, elemento da política externa da União, precisa de ser claramente explicada às regiões europeias, sob pena de se exacerbarem os egoísmos regionais face a regiões de terceiros países e precisa, ainda, de ser adequadamente traduzida e reforçada do ponto de vista orçamental.

Seja qual for a abordagem dominante ou a composição entre elas, nenhum modelo de política de coesão territorial resistirá à estagnação da economia europeia e internacional. Face a esta estagnação parece inevitável a emergência de uma zona de tensão que se estende da regionalização (ao centro) até ao regionalismo (na periferia), tendo como intermediária a política de coesão em sentido largo, ela própria subordinada à política macroeconómica de estabilidade imposta pelo pacto de estabilidade e o tratado orçamental.

Não há, pois, neste contexto competitivo tão severo, problemas regionais definitivamente resolvidos. Digamos que eles se tornam recorrentes em função do modo como cada região leva à prática a sua política regional, sabendo nós que diferentes estruturas político-administrativas e diferentes aplicações do princípio de subsidiariedade produzem desempenhos territoriais muito diferenciados e desiguais.

\section{OS CENÁRIOS DA GEOGOVERNANÇA PORTUGUESA E O RESCALING TERRITORIAL}

Chegados aqui, a questão nua e crua que se coloca à particular geogovernança portuguesa pode ser questionada e enunciada do seguinte modo:

Na transição longa e gradual de território-nação para território-região, estaremos nós, portugueses, na iminência de assistir, com paradoxal perplexidade, à progressiva irrelevância político-económica de um específico território nacional, em consequência, justamente, dos atributos abertos da economia $e$ da sociedade portuguesas, ou, ao contrário, assistiremos, pelos mesmos atributos, a uma reinvenção 
cosmopolita da sociedade portuguesa fundada na genuinidade da política doméstica e na valorização dos seus recursos humanos e respectivo assento territorial?

Ou dito de outro modo, o maior desafio para a União Europeia será o de conciliar diversidade e unidade, descentralização e integração; assim como os Estados-nações nasceram para acolher o capitalismo e fundar as economias nacionais, as regiões transnacionais poderão dar um contributo essencial para responder, simultaneamente, ao desenvolvimento da economia global e à coesão territorial.

Em espaço aberto e global, a continuidade do Estado-administração depende, em linha directa, da robustez e/ou fragilidade das organizações económicas e empresariais que lhes servem de suporte. Neste momento, depois de três anos de TROIKA, nada parece estar garantido. Tendo em mente a estrutura empresarial e organizacional da economia portuguesa é fácil concluir que ela não possui capacidade institucional e associativa suficientemente forte para absorver e processar a torrente de factores de transformação que são veiculados de fora para dentro do país.

No futuro próximo, a geogovernança portuguesa joga-se em dois grandes ciclos geoestratégicos: o ciclo atlântico da maritimidade em direcção aos EUA/Canadá, Brasil/América Latina e Africa/PALOP e o ciclo europeu da continentalidade em direcção à Ibéria, ao Euro-mediterrâneo e à Euro-ásia (COVAS, 2003). O alargamento, em curso, da zona económica exclusiva de Portugal está bem no centro deste duplo ciclo geoestratégico e justifica, só por si, esta mudança de orientação, se quisermos, $\underline{\text { o }}$ rescaling territorial do espaco português.

Enquanto global-player nestes dois grandes ciclos geoestratégicos, onde a geogovernança portuguesa readquire todo o seu significado, a grande incógnita, ou talvez não, é a de saber se Portugal se conseguirá libertar da Espanha para realizar esta aventura. E se não conseguir, qual o refluxo dessa parceria sobre a integração interna da própria economia ibérica, em especial, numa circunstância económica de estagnação como é aquela que vivemos neste momento. Como é evidente, não é fácil descobrir esse lugar geométrico de tantos destinos e parece quase impossível encontrá-los sem a presença da Espanha. Nada nos liberta da contingência, mas todas as possibilidades continuam em aberto, mesmo que a presunção da retórica nem sempre ajude. Com este aviso cautelar, vejamos algumas das possibilidades em aberto para exercitar a geogovernança portuguesa no cruzamento destes dois ciclos geoestratégicos (COVAS, 2003):

\section{1ª Hipótese: a plataforma de um corredor transatlântico: cenário MacPortugal}

Nesta hipótese, sempre imperfeita, o pior que nos poderia acontecer seria ter um país transformado em corredor transatlântico e em situação de duplo franchise europeu e americano, administrado, eventualmente, por parcerias de gestão luso-espanholas do mundo dos negócios; uma espécie de MacPortugal com assento maioritário na indústria do turismo;

\section{Peninsular}

2a. Hipótese: a formação de uma parceria ibérica transatlântica: cenário União

Nesta hipótese, imperfeita e incompleta, o melhor que nos poderia acontecer seria um entendimento bilateral global, nos planos político e empresarial, para uma acção conjunta, concertada, nos dois ciclos geoestratégicos referidos, em simultâneo com a reorganização

DRd - Desenvolvimento Regional em debate (ISSNe 2237-9029)

v. 5, n. 2, p. 25-47, jul./dez. 2015. 
profunda da economia ibérica que aproveitaria a logística latino-americana para ganhar escala e profundidade; Portugal seria apoiado pelo Brasil no lançamento desta parceria ou aliança latino-americana;

Entre o pior e o melhor destas duas possibilidades ou cenários podem alinhar-se outras hipóteses, porventura, mais verosímeis, por exemplo:

\section{brasileiro}

3. Hipótese: a formação de uma plataforma luso-brasileira: cenário luso-

Nesta hipótese, recentrada sobre a comunidade dos países de língua oficial portuguesa, a parceria luso-brasileira seria a alavanca principal a contrabalançar e complementar a parceria luso-espanhola, sendo Portugal o mediador oficial para introduzir a Espanha na CPLP;

\section{MEDOC}

4a. Hipótese: a formação de uma plataforma ibero-mediterrânica: cenário

Nesta hipótese, recentrada sobre o mar mediterrânico, e em especial sobre o mediterrâneo ocidental, a península ibérica seria o parceiro acreditado do mundo ocidental para esta sub-região;

\section{Latina \\ 5a. Hipótese: a formação de uma plataforma ibero-americana: cenário União}

Esta hipótese é, porventura, a mais consistente do ponto de vista das suas possibilidades estratégicas reais e aquela que, claramente, oferece maior profundidade e dimensão à economia ibérica, dado que lhe permite operar em vários níveis de desenvolvimento socioeconómico e aproveitar, por esse facto, as vantagens de localização e transferência daí decorrentes; além do mais, esta hipótese considera e engloba as duas hipóteses anteriores, sobretudo se pensarmos no aprofundamento da política externa e de segurança da União Europeia.

No terreno geoestratégico que procurámos delimitar, parece indubitável que o triângulo Espanha-Portugal-Brasil se constituirá, a médio e longo prazo, num terreno muito promissor se, entretanto, não for desencadeada, pelas piores razões, uma nova questão ibérica, traduzida, por exemplo, num desequilíbrio gritante das trocas comerciais e no correlativo refluxo orgânico da economia espanhola sobre a economia portuguesa, exacerbando radicalismos e regionalismos de ocasião.

Seja como for, Portugal não parece ter capacidade para, sozinho, ser um global-player no espaço transatlântico e ibero-americano. A este facto, acresce a eventualidade de a Espanha, ela própria, se desinteressar do espaço ibérico, dada a exiguidade do nosso próprio mercado, para se aproximar dos países grandes da União Europeia e realizar nesse espaço operações de maior prestígio, de up grading da sua economia, que the trarão benefícios acrescentados superiores aos da parceria ibérica. Não é demais recordar que Portugal é para Espanha, essencialmente, uma extensão comercial e, muito raramente, uma hipótese de localização produtiva. 
Tudo somado, o mais provável é que não existam estratégias e parcerias de desenvolvimento ibérico, pelo menos a curto prazo, mas, antes, movimentos empresariais de participações, alianças e consórcios, fusões e concentrações, de certa forma, a anarquia madura a que já nos referimos. Acresce que, no quadro, nos termos e nas profundas implicações territoriais do próximo tratado transatlântico de comércio livre (TTIP), tudo o que foi dito anteriormente assume proporções consideráveis. Não é mais possível que tudo se resuma ao mundo dos negócios e às suas decisões de oportunidade pura e simples. Sendo estas as evidências a curto prazo, então, a geogovernança portuguesa deveria privilegiar todas as oportunidades e todos os investimentos que requalificam o seu território e, no quadro das redes transeuropeias, defender o modelo policêntrico de ordenamento do território europeu.

De facto, no quadro amplo do TTIP e tratando-se de um território fronteiriço da União Europeia, não é politicamente aceitável, no mínimo, que essa fronteira, apontada ao mar alto e na confluência do corredor transatlântico, seja uma estreita porta de entrada ou de saída, servida por infra-estruturas e equipamentos sem profundidade logística e económica. De resto, é toda a península ibérica que vê requalificado o seu território interior e aumentada a fluidez dos seus corredores de penetração e, logo, a intensidade do tráfego de pessoas e mercadorias. É, também, nesta direcção que deve ser explorado o novo quadro político de responsabilidades territoriais, se aceitarmos que o acréscimo da expressão coesão territorial encerra, verdadeiramente, um significado político irrecusável. No mesmo sentido, a União adquire especiais responsabilidades no espaço das suas fronteiras exteriores, que são fronteiras de cidadania, mas, também, fronteiras de segurança externa colectiva. Assim será, por maioria de razão, se a União quiser chamar a si algumas funções de soberania externa (KEATING, 2013).

\section{A IMPORTÂNCIA DA GESTÃO MULTITERRITORIAL: UMA REFLEXÃO ACERCA DA NOVA SABEDORIA DOS LIMITES}

Nesta matéria, o nosso ponto de partida pode ser enunciado de acordo com o que diz Daniel Innerarity ... Na era da globalidade os sujeitos políticos aumentam o seu espaço de jogo na medida em que conseguem aumentar a sua riqueza cooperativa (INNERARITY, 2005).

\subsection{UMA NOVA SABEDORIA DOS LIMITES: A SOCIEDADE POLÍTICA LOCAL DO SÉCULO XXI}

Em nossa opinião a perspectiva do futuro abrangerá as seguintes promessas, a começar pela sociedade política local (COVAS; COVAS, 2014a). No plano da gestão local e municipal, o paradigma que daqui decorre contemplará um município mais aberto, mais cosmopolita, mais conectado e mais colaborativo. O decálogo que se segue ilustra bem este novo paradigma da gestão municipal (COVAS, 2015b) e (COVAS; COVAS, 2015a): 
1. Um município mais comunitário e federalista, com uniões de freguesias, associações de municípios e comunidades intermunicipais, praticando a governação multiníveis em múltiplas formas e modalidades de rescaling;

2. Um município mais aberto e interactivo em matéria de economia municipal, acertando com grupos de cidadãos uma nova crowd economy, isto é, práticas inovadoras de crowdsourcing, crowdfunding e crowdlearning;

3. Um município mais móvel e itinerante na prestação de serviços pessoais, inovando em matéria de serviços de mobilidade, transporte e bancos de tempo, tendo em vista a criação de uma genuína economia solidária no concelho;

4. Um município muito mais verde em matéria de economia dos $4 \mathrm{R}$ (reduzir, reciclar, reparar e reutilizar) e muito mais eficiente em matéria de recursos ociosos criando uma dinâmica economia colaborativa no que diz respeito ao reaproveitamento destes recursos;

5. Um município muito mais virado para a economia criativa e cultural em tudo o que diz respeito à gestão de recursos intangíveis e simbólicos, isto é, uma verdadeira economia imaterial;

6. Um município muito mais polivalente, horizontal e interactivo no que diz respeito à sua orgânica interna, que se traduzirá numa nova relação funcional front-office versus back-office, acompanhada de uma alteração substancial do seu capital social;

7. Um município cada vez mais peer to peer, com menos hierarquia e mais heterarquia, um verdadeiro par interpares, por exemplo, em matéria de parcerias público-privadas mais inteligentes territorialmente;

8. Um município menos fiscalista e mais contratualista no plano da engenharia financeira, por exemplo, com um funding muito mais diversificado e imaginativo junto dos grupos de interesse locais e regionais;

9. Um município mais cristalino e transparente no que diz respeito à accountability municipal, isto é, com uma monitorização das políticas públicas muito mais interactiva e just in time;

10. Um município com via verde jovem no domínio da economia digital, isto é, mais aberto e imaginativo para a sua população jovem, por via de diversas plataformas inteligentes desde simples espaços de co-working até estruturas de FabLab para a produção de protótipos industriais.

Como facilmente se observa, o município do século XXI deixa de ser um espaço de stocks para passar a ser um espaço de fluxos, uma espécie de plataforma móvel em permanente remontagem. A inteligência colectiva será a sua principal motivação e objectivo. 


\subsection{UMA NOVA SABEDORIA DOS LIMITES: O EXEMPLO DA COOPERAÇÃO TRANSFRONTEIRIÇA}

A cooperação transfronteiriça é, seguramente, um dos níveis mais interessantes de rescaling e governança territorial. As reflexões que se seguem, em redor do que designámos como uma nova sabedoria dos limites, visam aprofundar a cooperação territorial entre regiões de fronteira, a partir da experiência da Euro-região do Eixo Atlântico. Uma primeira versão destas reflexões foi publicada no $n^{\circ} 16$ da revista do Eixo Atlântico (COVAS, 2009). Trata-se aqui de encontrar um nível de pertinência governativa para a multiterritorialidade, de tal maneira que se reduzam e convirjam, a um tempo, o grau de generalidade das políticas públicas do centro e o grau de especificidade das políticas públicas locais, em ordem à eliminação dos custos de contexto fronteiriços e à geração de novos benefícios de contexto transfronteiriços.

\section{1ª reflexão: dos espaços delimitados aos espaços des-limitados}

Sabemos que a construção do território do Estado-nação foi um processo político de delimitação do espaço por via de uma fronteira de soberania estadual. Não se trata, agora, de eliminar os limites, que a memória sempre registará, trata-se de os reformular através da sua conversão num recurso cooperativo ao serviço de uma soberania partilhada dos territórios. A des-limitação dos espaços transfronteiriços, ao provocar uma libertação da sua energia vital, será uma fonte inesgotável de realidade emergente. Os territórios de geometria variável e flexível estão, portanto, numa excelente posição para capturar essa energia historicamente acumulada que brotará da des-limitação dos espaços de fronteira.

\section{$2^{\text {a }}$. reflexão: dos territórios em rede aos territórios-rede}

$\mathrm{Na}$ sociedade da informação e do conhecimento o número de redes cresce exponencialmente. Mas os territórios em rede não se confundem com os territórios-rede. Os primeiros vivem mergulhados num imenso mar de possibilidades virtuais, os segundos já revelam uma intencionalidade, uma estratégia e um programa de acção. Nos territórios em rede ainda são os meios a determinar uma parte significativa dos fins da cooperação territorial, é mesmo provável que o deslumbramento tecnológico e as redes de informação ditem uma parte importante das normas de funcionamento da jovem organização territorial. Os territórios-rede, pelo contrário, já são capazes de gerar uma imagem auto-referencial suficiente e uma intencionalidade política e, nesse exercício de reflexão interna, conceber e construir uma administração-rede imaginativa, modesta, ágil e empreendedora, que faça da cooperação territorial transfronteiriça um novo recomeço e uma nova identidade multiterritorial. 


\section{$3^{\mathrm{a}}$. reflexão: da sociedade do conhecimento à responsabilidade perante o futuro}

A sociedade do conhecimento proporciona-nos tanto futuro como incerteza perante o futuro. A cooperação territorial descentralizada (CTD), sob a forma de cooperação transfronteiriça, é um excelente instrumento para reduzir as zonas de incerteza perante o futuro porque pode contribuir eficazmente para prevenir o risco moral interfronteiriço e desenhar cenários possíveis de governança territorial, para lá de organizar uma concorrência praticável entre as diferentes parcelas de território fronteiriço assim como uma base comum para as suas respectivas relações exteriores. Face a tanto futuro vigora, pois, o princípio da responsabilidade perante o futuro.

\section{4a reflexão: interdependência, contingência e custos de transacção multiterritorial}

A gestão multiterritorial é muito exigente: alta conectividade, multi-escalas de governo e administração, multipolaridade, multi-identidade. Na cooperação transfronteiriça luso-espanhola a questão essencial é saber se as jovens organizações multiterritoriais são capazes de gerar novos lugares-globais, por cima ou para além das suas entidades constituintes, ou se, pelo contrário, são organizações obedientes, estritamente mandatadas para levar a cabo um programa modesto, de baixa intensidade inter-organizacional, com baixos custos de transacção, aqueles que os municípios fundadores e os programas europeus de cooperação lhes consentem. Dito de outro modo, as organizações de cooperação territorial não podem ser eternamente um pretexto à boleia de uma oportunidade, elas próprias vítimas de estratégias excessivamente institucionalizadas e municipalizadas. Esta frágil relação umbilical é, de algum modo, o pecado original da cooperação territorial descentralizada.

\section{5'. reflexão: dos governos de autoridade aos governos de contexto multiterritorial}

Como refere Innerarity, "[...] apresenta-se actualmente à política o dever de transitar da hierarquia para a heterarquia, da autoridade directa para a conexão comunicativa, da posição central para a composição policêntrica, do comando unilateral para a implicação policontextual" (INNERARITY, 2005, p. 144).

Num sistema de governação multiníveis (multi-level governance) a questão crucial dos governos de contexto, num plano intermédio de cooperação territorial, é, em primeiro lugar, eliminar os custos de contexto transfronteiriços e, em segundo lugar, gerar os benefícios de contexto inovadores que façam subir o patamar da cooperação territorial. Benefícios de contexto em três áreas fundamentais: no reforço da densidade institucional e do capital social multiterritorial, na organização das relações exteriores do novo agrupamento territorial, na forma de lidar com os efeitos externos das políticas públicas. A mesoeconomia do Eixo Atlântico é o lugar geométrico destes efeitos, descendentes (políticas do centro) e ascendentes (políticas locais), ao mesmo tempo que se esforça por oferecer, em permanência, uma ficção de consenso em ordem a manter, num plano elevado, o fluxo de energia e o caudal de iniciativas provenientes dos vários territórios em presença. 


\section{$6^{a}$. reflexão: das velhas centralidades para as novas centralidades}

Sabemos já que a inércia do crescimento económico pode conduzir a uma metropolização excessiva e, correlativamente, a uma produção apreciável de efeitos externos negativos cuja correcção polariza ainda mais a metropolização em curso. Neste contexto, de quase círculo vicioso, a cooperação territorial descentralizada pode ser não apenas um instrumento de mitigação/adaptação/compensação de subterritórios em perda como, sobretudo, um veículo fundamental de criação de novos lugares-globais que contrariem estruturalmente essa mesma metropolização e conduzam a uma cidade-região mais policêntrica. De facto, é preciso estar avisado face a um excesso de capitalidade ou de metropolização, na exacta medida em que uma boa ideia de cooperação territorial descentralizada pode, desde o início, ficar refém de pesados custos de contexto, estando impedida, na prática, de levar a bom termo a «outra parte» do seu programa, isto é, a geração de benefícios de contexto, os novos lugares-globais e as pequenas redes multilocais.

\section{7 . reflexão: a coopeticão territorial em nome de uma sociedade multiterritorial de aprendizagem e conhecimento mútuo}

A política pós-estadual é cada vez mais uma política sem centro e sem vértice. Numa sociedade de riscos globais, os bens globais e colectivos têm de ser organizados de modo cooperativo sob pena de não haver, sequer, benefícios de contexto para o funcionamento dos mercados globais. O conceito de coopetição (COVAS, 2009) tem, neste contexto, o valor simbólico de um programa, a um tempo cooperativo e competitivo. Cria uma tensão na realidade para ser competitiva, mas abre, também, uma profunda reflexão sobre os métodos e os conteúdos da cooperação interregional, seja nas suas relações internas ou nas relações exteriores. Estamos em crer que um programa para a coopetição transfronteiriça incluirá: a arte da localidade e das redes locais, a arte do associativismo e das redes de interconhecimento, o debate público sobre os novos bens colectivos e os novos lugaresglobais, a economia dos ecossistemas e das paisagens globais e a geração de novas amenidades e interioridades, um programa de benchmarking de boas práticas empresariais, a promoção diplomática das relações exteriores da nova entidade multiterritorial, a promoção da economia do simbólico e do imaginário na construção de um espaço público multiterritorial. Temos um longo caminho pela frente. É imperioso que o todo seja maior do que a soma das partes (COVAS, 2009). 


\subsection{UMA NOVA SABEDORIA DOS LIMITES: O EXEMPLO DAS COMUNIDADES INTERMUNICIPAIS (CIM)}

O país constituiu muito recentemente 23 comunidades intermunicipais (CIM) ${ }^{6}$, a maioria delas coincidente com as NUTS III $^{7}$ (sub-regiões das NUTS II); trata-se de um nível de programação, planeamento e implementação de políticas muito relevante para reconsiderar todo o sistema de desenvolvimento regional, local e rural do país (COVAS, 2015a). Recordemos que o país tem praticamente em cada capital de distrito um instituto politécnico ou uma universidade cujas áreas de influência e acção abrangem as CIM e as NUTS III e que estas instituições precisam urgentemente de refrescar e renovar a sua missão e de ganhar um suplemento de legitimação num tempo histórico de grande exigência para o país. Acresce que, no mesmo âmbito territorial, o país tem associações empresariais, parques industriais e grupos empresariais que precisam urgentemente de fazer a sua prova de vida, de se recapitalizar e rejuvenescer e demonstrar que não são meros simulacros empresariais mas verdadeiros projectos empresariais.

A triangulação entre estas três entidades - as comunidades intermunicipais, os institutos politécnicos e universidades e as associações empresariais - poderia dar origem a um pacto ou convenção de desenvolvimento territorial para o nível NUTS III/ CIM com o objectivo de comprometer as três entidades num projecto de desenvolvimento regional para o período 2015-2020. Esta convenção ou pacto de desenvolvimento territorial para o nível NUTS III/CIM pode e deve ser concebida como um modelo de mérito e resultados; as metas quantificadas e a monitorização permanente realizada por uma estrutura de missão permitiriam não só definir resultados e prémios de desempenho como, também, a avaliação interna do processo e as condições de renovação do contrato de desenvolvimento territorial.

No mesmo contexto, e no quadro de uma filosofia de contratos de desenvolvimento territorial, o governo central seria convidado a apresentar uma proposta de reforma da administração regional sob a forma de uma lei-quadro da descentralização políticoadministrativa, onde o nível NUTS II seria constituído como a sede apropriada para uma nova racionalidade e inteligência territoriais, em especial, naquilo que são hoje as missões e as funções das comissões de coordenação e desenvolvimento regional e, bem assim, dos serviços regionais em geral, no sentido da formação de um executivo regional com um mandato que

\footnotetext{
${ }^{6} \mathrm{CIM}$ (Comunidades Intermunicipais). As comunidades intermunicipais de Portugal (CIM) correspondem a unidades territoriais portuguesas, e constituem-se como o segundo tipo de entidade intermunicipal a par das áreas metropolitanas de Lisboa e do Porto. De acordo com a Lei n. ${ }^{\circ}$ 75/2013 de 12 de Setembro, as atuais comunidades intermunicipais são 21: Algarve, Alentejo Central, Alentejo Litoral, Alto Alentejo, Alto Minho (Minho-Lima), Alto Tâmega, Ave, Baixo Alentejo, Beira Baixa, Beiras e Serra da Estrela, Cávado, Douro, Lezíria do Tejo, Médio Tejo, Oeste, Região de Aveiro, Região de Coimbra, Região de Leiria, Tâmega e Sousa, Terras de Trás-os-Montes, Viseu Dão Lafões.

${ }^{7}$ As NUTS (Nomenclatura de Unidades Territoriais - para fins Estatísticos) designam as sub-regiões estatísticas em que se divide o território dos países europeus, incluindo Portugal. De acordo com o Regulamento (CE) $\mathrm{n}^{\circ}$ 1059/2003 do Parlamento Europeu e do Conselho, de 26 de Maio de 2003, relativo à instituição de uma Nomenclatura Comum das Unidades Territoriais Estatísticas (NUTS), estas estão subdivididas em 3 níveis: NUTS I, NUTS II e NUTS III. No caso de Portugal, as NUTS I referem-se à Portugal Continental, Região Autónoma dos Açores e Região Autónoma da Madeira. As NUTS II: Norte; Centro; Lisboa; Alentejo; Algarve; Região Autónoma dos Açores e Região Autónoma da Madeira. As sete NUTS II, por sua vez, se subdividem em 30 NUTS III. Exemplos de NUTS III: Serra da Estrela, Grande Lisboa, Baixo Alentejo e Península de Setúbal.
}

DRd - Desenvolvimento Regional em debate (ISSNe 2237-9029)

v. 5, n. 2, p. 25-47, jul./dez. 2015. 
poderia ser expresso, por exemplo, através de uma resolução do conselho de ministros após parecer favorável do Conselho Regional para o efeito.

Nesta sequência, um contrato assinado com a administração central firmaria os termos da convenção de desenvolvimento territorial; para dar corpo ao projecto seria utilizado o instrumento ITI (investimento territorial integrado) ${ }^{8}$ tal como está previsto nos normativos para o próximo período de programação. Para levar a cabo o projecto de desenvolvimento e a implementação do ITI seria criada uma governança dedicada com base nos três principais parceiros promotores e, para esse efeito, criado um actor-rede capaz de dar corpo a uma estrutura de missão dotada de competências executivas no território da CIM/NUTS III. No mesmo contrato de desenvolvimento territorial, ficariam os três promotores principais obrigados à apresentação de uma proposta de reforma da administração pública multilocal da CIM que considere não apenas uma nova estrutura de bens públicos para o território-rede em construção como uma institucionalidade adaptada ao projecto de desenvolvimento em ordem à formação de novos bens comuns.

Finalmente, no âmbito desta filosofia de contratos de desenvolvimento para territóriosrede de nível NUTS III/CIM, o governo central proporia um quadro legal e financeiro de incentivos à construção desta administração dedicada e à formação de redes de cooperação e extensão empresariais atendendo ao universo de microempresas que constituem o tecido empresarial do interior do país.

\subsection{UM NOVO QUADRO CONCEPTUAL PARA A GESTÃO MULTITERRITORIAL}

Depois desta incursão multiterritorial, a tabela $n^{0} 1$ ajuda-nos a perceber melhora a dinâmica da gestão multiterritorial e o seu novo enquadramento teórico-conceptual:

Tabela 1 - A dinâmica da gestão multiterritorial

\begin{tabular}{|l|}
\hline \multicolumn{1}{|c|}{ Governança multiníveis (Multi-level governance): uma nova sabedoria dos limites } \\
\hline Do governing ao governance e à governability \\
Dos territórios-zona aos territórios-rede \\
Da competitividade à coopetitividade \\
Do rescaling à gestão multiterritorial descentralizada \\
Dos universos virtuais à sociedade colaborativa \\
Da autoridade directa para a conexão comunicativa e policontextual \\
\hline
\end{tabular}

Fonte: Covas e Covas (2015d).

A formação da aldeia global é uma boa metáfora para esta nova sabedoria dos limites que temos à nossa frente. A aldeia global é uma construção permanente, tudo caminha para dentro da aldeia, os problemas tornaram-se comuns, por isso, a governação vertical, hierárquica e autoritária (o governing) deixou de ser apropriada para a complexidade do problema (governance e governability). $\mathrm{O}$ abaixamento das fronteiras nacionais colocou os actores principais face a face e esse facto obrigou-os a rever os seus processos e ${ }^{8}$ ITI (Investimento Territorial Integrado). Para informação completa
http://ec.europa.eu/regional_policy/sources/docgener/informat/2014/iti pt.pdf.

DRd - Desenvolvimento Regional em debate (ISSNe 2237-9029)

v. 5, n. 2, p. 25-47, jul./dez. 2015. 
procedimentos de policy-making decision. Começa, assim, a transição dos territórios-zona para os territórios-rede (COVAS; COVAS, 2014a). No interior da aldeia global, os vizinhos procuram a cooperação mais do que a competição, eles são mais coopetitivos, tendo em vista organizar os mercados de trabalho de uma forma cooperativa e solidária, ao mesmo tempo que a gestão multiterritorial descentralizada se torna a regra com a formação dos territóriosrede de geometria variável (COVAS, 2009).

Nesta nova sabedoria dos limites os universos virtuais ocupam um lugar privilegiado, sempre em busca dos marcadores simbólicos e culturais que ajudam a recriar os sinais distintivos dos territórios e, portanto, a sua renovação e reinvenção. Neste percurso longo e difícil, a sociedade colaborativa tem um papel primordial a desempenhar, sobretudo no que diz respeito à criação de uma conexão comunicativa mais fértil e fecunda que hoje está nas mãos de muitas burocracias locais, regionais, nacionais e europeias (COVAS; COVAS, 2015d).

\section{CONCLUSÕES}

A relação entre várias escalas espaciais - a globalização, a integração europeia, a integração ibérica e a descentralização político-administrativa infranacional - está cheia de contradições mas, também, de ensinamentos. Os processos de respacing e rescaling operam em todos os sentidos (KEATING, 2013). Veja-se, por exemplo, neste momento, a formação de grandes espaços transcontinentais, como o Transpacífico e o Transatlântico e, ao mesmo tempo, a proposta de referendo no Reino Unido para sair da União Europeia ou, ainda, os movimentos independentistas no interior de alguns Estados-membros da União Europeia.

Entretanto, a geografia política europeia acelera e precipita-se a um ritmo vertiginoso. Desaparecem as fronteiras económicas e políticas na Europa Ocidental, reaparecem as fronteiras nacionais no leste europeu e na Ex-União Soviética. O desaparecimento das fronteiras nacionais na União Europeia faz irromper na cena política as regiões cuja história é, por vezes, anterior à do próprio Estado-nacional que as unificou, umas vezes pacificamente outras vezes pela força. Da mesma forma que o sistema político pré-nacional englobava principados, reinos e impérios, podemos especular dizendo que o sistema político protofederal europeu incluirá, muito provavelmente, uma pluralidade de protagonistas tais como: regiões-nacionais, cidades-estado, regiões metropolitanas, colectividades territoriais infranacionais, regiões transfronteiriças, macrorregiões transnacionais, organizações internacionais, empresas multinacionais, instituições supranacionais, organizações nãogovernamentais de âmbito europeu e global, etc.

A natureza exploratória e prospectiva deste pequeno ensaio diz-nos que, se a tendência se confirmar a médio e longo prazo, o monopólio político tradicional do Estado-nacional será partilhado com muitos outros actores, sendo que o novo equilíbrio de poderes e a sua governabilidade, constituirão, de facto, a originalidade do modelo europeu. Neste enquadramento, os problemas de multi-level governance e de multi-escalaridade serão frequentes e determinantes. 
No grande cenário europeu, por exemplo, os movimentos de dimensão transcontinental, num horizonte temporal alargado, determinarão a formação de macrorregiões europeias transnacionais (por exemplo, a Península Ibérica), uma espécie de um novo concerto dos territórios, onde, porventura, reaparecerão as questões antigas do equilíbrio de poderes e da governabilidade multiníveis. O respacing e o rescaling, seja no plano intra-europeu ou transcontinental, serão um factor recorrente de perturbação social e política (KEATING, 2013).

Ao contrário, no plano da microgeoeconomia, as redes colaborativas e os territóriosrede anunciarão, muito provavelmente, a emergência da sociedade colaborativa e de uma renovada governança territorial.

Finalmente, importará saber, neste contexto transnacional e trans-regional, se pode emergir, paradoxalmente, um Estado-nacional transfigurado, com poderes reforçados de negociação e regulação, intermediário e mediador da pluralidade de poderes infra e supranacionais. Vamos aguardar para ver.

\section{REFERÊNCIAS}

BAUMAN, Z. Modernidade Líquida. Rio de Janeiro: Zahar Editora, 2001.

BECK, U.; GIDDENS, A.; LASH, S. Reflexive modernization: politics, tradition and aesthetics. Cambridge: Polity Press, 2004.

BERGER, P.; LUCKMANN, T. The Social Construction of Reality. Nova Iorque: The Penguin Press, 1967.

BOURDIEU, P. Les structures sociales de l'economie. Paris: Seuil, 2000.

CASTELLS, M. A sociedade em rede. 3.ed. São Paulo: Editora Paz e Terra, 2000a, v. I, (1 ${ }^{\text {a }}$ Edição 1999).

CASTELLS, M. O poder da identidade. 2.ed. São Paulo: Editora Paz e Terra, 2000b, v. II,

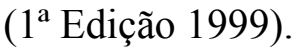

CASTELLS, M. Fim de milénio. 2.ed. São Paulo: Editora Paz e Terra, 2000c, v. III, (1 ${ }^{\text {a }}$ Edição 1999).

COLEMAN, J. Social capital in the creation of human capital. The American Journal of Sociology, Sup, pp. 95-120, 1988.

COVAS, A. M. O futuro da gestão do poder local. Palestra proferida na Câmara Municipal de Loulé, 26 fev., $2015 \mathrm{a}$.

COVAS, A. M. Uma viagem pelo Grande País do Interior. Jornal de Negócios, 14 abr., $2015 b$.

COVAS, A. M. União Europeia: os bens comuns da futura federação europeia. Lisboa: Editora colibri, 2013. 
COVAS, A. M. O eixo atlântico e a "coopetição" transfronteiriça. Decálogo para uma nova sabedoria dos limites. Eixo Atlântico, n. 16, p. 388-396, 2009.

COVAS, A. M. Portugal e a constituição europeia. Lisboa: Editora Colibri, 2003.

COVAS, A. M.; COVAS, M. M. C. M. Multiterritorialidades I: Temas e problemas de governança e desenvolvimento territoriais. Lisboa: Editora Colibri, 2015a.

COVAS, A. M.; COVAS, M. M. C. M. Sociedade do conhecimento, escalas de governo e governança territorial: a sociedade portuguesa em transição. Actas do II Congresso Internacional SETED-ANTE. Santiago de Compostela, 1-3 jul. 2015 b.

COVAS, A. M.; COVAS, M. M. C. M. A dieta mediterrânica - a criação de uma cadeia de valor multifuncional. Para uma nova inteligência territorial no rural tradicional algarvio. Uma abordagem exploratória. Revista de Geografia e Ordenamento do Território, n. ${ }^{\circ}$ 7, (30 de Junho), Centro de Estudos de Geografia e Ordenamento do Território (CEGOT), pp. 111-128. GOT, Geografia e Ordenamento do Território, Revista Electrónica Centro de Estudos de Geografia e Ordenamento do Território, http://cegot.org, 2015c.

COVAS, A. M.; COVAS, M. M. C. M. A Dieta Mediterrânica - Entre a tradição e a inovação - Uma oportunidade para o rural tradicional algarvio, Definindo Dieta Mediterrânica Património Cultural da Humanidade. Faro: Universidade do Algarve, p. 276 - 286, 2015d.

COVAS, A. M.; COVAS, M. M. C. M. Os territórios-rede: a inteligência territorial da $2^{\text {a }}$ ruralidade. Lisboa: Editora Colibri, 2014a.

COVAS, A. M.; COVAS, M. M. Os territórios-rede: uma nova inteligência territorial em Portugal, in Dallabrida, Valdir Roque (Org.) Desenvolvimento territorial: políticas públicas brasileiras, experiências internacionais e a Indicação Geográfica como referência, S. Paulo: Editora LiberArs, p: 97-119, 2014 b.

COVAS, A. M.; COVAS, M. M. C. M. Da micreogeoeconomia aos territórios-rede. X Coloquio Ibérico de Estudios Rurales. Territorios rurales, Agriculturas locales y Cadenas alimentarias, (X CIER). Editorial, Universitat Politècnica de València (UPV), pp: 137-140. Editado por: Asociación Española de Economía Agraria, Editorial Universitat Politècnica de València, www.lalibreria.upv.es / Ref: 6193_01_01_01. Palencia, 16-17 de Outubro, 2014c.

COVAS, A. M.; COVAS, M. M. C. M. A construção social dos territórios-rede: A inteligência territorial da $2^{\mathbf{a}}$ ruralidade. Brasil: Editora Liber Ars, [eBook Kindle], 2014d.

COVAS, A. M.; COVAS, M. M. C. M. A construção social dos territórios-rede da $2^{\text {a }}$ ruralidade: dos territórios-zona aos territórios-rede, construir um território de múltiplas territorialidades. Revista de Geografia e Ordenamento do Território, n. ${ }^{\circ} 3$ (30 de Junho). Centro de Estudos de Geografia e Ordenamento do Território (CEGOT), pp. 7 a 40, 2013. http://cegot.org/ojs/index.php/GOT/issue/current.

COVAS, A. M.; COVAS, M. M. C. M. A caminho da $2^{\text {a }}$ ruralidade: a microgeoeconomia de novos sistemas territoriais - A experiência do Projecto Querença. 1st International Meeting - Geography \& Politics, Policies and Planning. CEGOT. E-book Geography\&PPP. 
pdf.N¹:528-540,2013. Disponível em:

$<$ https://docs.google.com/file/d/0B8tVjRNsbUlbZk52OVNIdzU0WEE/edit?pli=1>

COVAS, A. M.; COVAS, M. M. C. M. Em busca de uma racionalidade territorial multiníveis nos processos de governança regional: o exemplo da Região do Algarve, DRd-

Desenvolvimento Regional em debate, Ano 3, N. 2, pp. 65-85, julho/dezembro/2013a.

COVAS, A. M.; COVAS, M. M. C. M. A construção social dos territórios-rede da $2^{\text {a }}$ ruralidade: dos territórios-zona aos territórios-rede - construir um território de múltiplas territorialidades. Revista de Geografia e Ordenamento do Território, n. ${ }^{\circ}$ 3, (30 de Junho), Centro de Estudos de Geografia e Ordenamento do Território (CEGOT), 2013b, pp: 7-40, PDF: 43-66. http://cegot.org/ojs/index.php/GOT/issue/current

COVAS, A. M.; COVAS, M. M. C. M. A caminho da $2^{\mathrm{a}}$ ruralidade: a microgeoeconomia de novos sistemas territoriais - A experiência do Projecto Querença, $\mathbf{1}^{\text {st }}$ International Meeting - Geography \& Politics, Policies and Planning, CEGOT. E-book_Geography\&PPP.pdf. N ${ }^{o}$ 1, pp: 528-540, 2013c.

COVAS, A. M.; COVAS, M. M. C. M. A caminho da $2^{\text {a }}$ ruralidade, uma introdução à temática dos sistemas territoriais. Lisboa: Colibri, 2012.

COVAS, A. M.; COVAS, M. M. C. M. A Grande Transição, pluralidade e diversidade no mundo rural. Lisboa: Colibri, 2011.

DALLABRIDA, V. R. (Org.) Território, identidade territorial e desenvolvimento regional. S. Paulo: Editora Liber Ars, 2013.

DALLABRIDA, V. R. Território e Desenvolvimento Sustentável: Indicação Geográfica da erva-mate de ervais nativos no Brasil. Informe Gepec, Toledo, (PR), Vol. 16, n.1, pp. 42-69, 2012.

DALLABRIDA, V. R. (Org.) Governança Territorial e Desenvolvimento: descentralização político-administrativa, estruturas subnacionais de gestão do desenvolvimento e capacidades estatais. Rio de Janeiro: Garamond, 2011.

FLIGSTEIN, N. Theory of fields. Oxford: Oxford University Press, 2012.

FLIGSTEIN, N. The architecture of markets: An economic sociology of twenty-firstcentury capitalist societies. Princeton University Press, 2001.

FRIEDMAN, T. Quente, plano e cheio. Actual Editora, 2008.

FRIEDMAN, T. O mundo é plano: uma breve história do século XXI. Actual Editora, 2006.

FUKUYAMA, F. The end of History and the last man. New York: The Free Press, 1992.

GIDDENS, A. Runaway world. How globalisation is reshaping our lives. London: Profile Books, 1999. 
HABERMAS, J. The Structural Transformation of the Public Sphere. Cambridge: Polity Press, $1^{a}$ Edição 1962, (Última edição 1994).

HABERMAS, J. Técnica e Ciência como “Ideologia". Lisboa: Edições 70, 1ª Edição 1968, (última edição 1994).

HABERMAS, J. Legitimation Crisis. London: Heinemann, $1^{a}$ Edição 1973, (última edição 1976a).

HABERMAS, J. Communication and the Evolution of Society. Cambridge: Cambridge Polity Press, $1^{\text {a }}$ Edição 1976b, (última edição 1995).

HABERMAS, J. The Theory of Communicative Action: Reason and the Rationalization of Society (vol. 1). Cambridge: Cambridge Polity Press, 1981a (1ª edição), 1986a (última edição).

HABERMAS, J. The Theory of Communicative Action: The Critique of Functionalist Reason, (vol. 2), Cambridge: Cambridge Polity Press, 1981b (1ª edição), 1986 (última edição).

HABERMAS, J. Moral Consciousness and Communicative Action. Cambridge: Cambridge Polity Press, 1983 (1 ${ }^{\mathrm{a}}$ edição), 1990 (última edição).

HABERMAS, J. A Nova Opacidade: A Crise do Estado-Providência e o Esgotamento das Energias Utópicas. Revista Comunicação e Linguagens, Dezembro. Porto: Edições Afrontamento, 1985a.

HABERMAS, J. O Discurso Filosófico da Modernidade. Lisboa: Publicações Dom Quixote, 1985b (1ª edição), 1990 (última edição).

HABERMAS, J. Postmetaphysical Thinking. Cambridge, Cambridge, Polity Press, 1988 ( $1^{\text {a }}$ edição), 1998a (última edição).

HABERMAS, J. The New Conservatism. Cambridge, Cambridge, Polity Press, 1989.

HABERMAS, J. Justification and Application. Cambridge, Cambridge, Polity Press, 1991 (1ª edição), 1993 (última edição).

HABERMAS, J. Between Facts and Norms. Contributions to a Discourse Theory of Law and Democracy. Cambridge, Cambridge, Polity Press, 1992 (1ª edição), 1996a (última edição).

HABERMAS, J. The Inclusion of the Other. Studies in Political Theory. Cambridge, Cambridge, Polity Press, 1996b (1ª edição), 1998b (última edição).

HABERMAS, J. The Postnational Constellation. Political Essays. Cambridge, Cambridge, Polity Press, 1998b (1 $1^{a}$ edição), 2001 (última edição).

HABERMAS, J. The Divided West. Cambridge, Cambridge, Polity Press, 2006.

HABERMAS, J. Europe. The Faltering Project. Cambridge, Cambridge, Polity Press, 2009.

DRd - Desenvolvimento Regional em debate (ISSNe 2237-9029) 
HABERMAS, J. An Awareness of What is Missing: Faith and Reason in a Post-secular Age. Cambridge, Cambridge, Polity Press, 2010.

HAESBAERT, R. O mito da desterritorialização. Rio de Janeiro: Bertrand Brasil, 2 ed., 2006.

INNERARITY, D. O futuro e os seus inimigos. Lisboa: Editora Teorema, 2011.

INNERARITY, D. O novo espaço público. Lisboa: Editora Teorema, 2010.

INNERARITY, D. A sociedade invisível. Lisboa, Editora Teorema, 2009.

INNERARITY, D. A transformação da política. Lisboa: Editora Teorema, 2005.

KEATING, M. Rescaling the European State. Oxford: Oxford University Press, 2013.

LIPOVETSKY, G. A felicidade paradoxal: ensaio sobre a sociedade do hiperconsumo. Lisboa: Edições 70, 2015.

LIPOVETSKY, G. La société de déception. Paris: Textuel, 2006.

LIPOVETSKY, G. A era do vazio. Ensaios sobre o individualismo contemporâneo. Barueri: Manole, 2005.

LIPOVETSKY, G.; SERROY, J. O capitalismo estético na era da globalização. Lisboa: Edições 70, 2014.

LIPOVETSKY, G.; SERROY, J. A cultura mundo: resposta a uma sociedade desorientada. Lisboa: edições 70, 2010a.

LIPOVETSKY, G.; SERROY, J. O ecrã global. Lisboa: Edições 70, 2010 b.

OSTROM, E. Understanding Institutional Diversity. Princeton University Press, 2005a.

OSTROM, E. Doing institutional analysis. In Handbook of New Institutional Economics. Ménard and Shirley Eds., Springer, p. 819-848, 2005b.

PECQUEUR, B.; ZIMMERMANN, J. Economies de proximités. Paris: Hermés, 2004.

PEREIRA, M. Da governança à governança territorial colaborativa: uma agenda para o futuro do desenvolvimento regional. DRd-Revista de Desenvolvimento em Debate, a. 3, n. 2, p. $52-65,2013$.

PEREIRA, M. Desafios contemporâneos do ordenamento do território: para uma governabilidade inteligente do território. Revista de Prospectiva e Planeamento, Lisboa, Vol. 16, p. 78-101, 2009.

POLANY, K. A grande transformação: as origens da nossa época. 9.ed. Rio de Janeiro: Editora Campus, 2000. 
RIFKIN, J. The zero marginal cost society: the internet of things, the collaborative commons, and the eclipse of capitalism. New York: Palgrave Macmillan, 2014a.

RIFKIN, J. A terceira revolução industrial: como a nova era da informação mudou a energia, a economia e o mundo. Lisboa: Bertrand Editora, 2014b.

RIFKIN, J. A era do acesso. Lisboa: Editorial Presença, 2001.

RIFKIN, Jeremy. O século da biotecnologia. São Paulo: MakronBooks, 1998.

RIFKIN, Jeremy. La fin du travail. Paris: La Découverte, 1996. - (Cahiers Libres. Essais)

ROSNAY, J. Surfer la vie: comment sur-vivre dans la societé fluide. www.surferlavie.com, LLL, 2012.

VIRILIO, P. Velocidade e política. São Paulo: Estação Liberdade, 1996.

WILLIAMSON, O. The new institutional economics. Journal of Economic Literature, v. 38, n. 3, p. 595-613, 2000.

Artigo recebido em: 31/08/2015

Artigo aprovado em: 01/10/2015 